\title{
Сельскохозяйственная кооперация
}

\section{в условиях новых вызовов и угроз:} от теоретических дискуссий к хозяйственной практике

\author{
С. Г. Головина ${ }^{1 凶}$, Л. Н. Смирнова ${ }^{2}$ \\ ${ }^{1}$ Уральский государственный аграрный университет, Екатеринбург, Россия \\ ${ }^{2}$ Курганская государственная сельскохозяйственная академия имени Т. С. Мальцева, \\ Лесниково, Россия \\ ${ }^{\square}$ E-mail:kkrav84@mail.ru
}

\begin{abstract}
Аннотация. В сложившейся социально-экономической, политической и институциональной среде, прежде всего в условиях новых вызовов и угроз (таких как санкционные ограничения, природные катаклизмы, эпидемии и пандемии), детерминирующих высокую нестабильность в деятельности аграрных производителей, особую значимость в развитии аграрной экономики, сельских сообществ и сельских территорий обретает сельскохозяйственная кооперация. Как доказывают ретроспективные исследования, аграрные кооперативы всегда становятся востребованными в наиболее сложные для сельского хозяйства (и экономики в целом) периоды, предельно актуализируя в это время соответствующие теоретические и прикладные изыскания. Изучение и анализ трудов ученых по вопросам современного состояния сельскохозяйственной кооперации, ее проблем и потенциала в решении задач совершенствования аграрного производства и гармоничного развития сельских территорий позволяют заключить, что, несмотря на наличие (в представленных научному сообществу обзорных материалах) описаний эволюции кооперативной мысли и резюмирующих дискуссий по теории кооперации, достижения последних лет все же не нашли в них должного отражения. Цель данной работы - обобщение наиболее содержательных результатов исследований мирового уровня о деятельности сельскохозяйственных кооперативов во флуктуирующей (иногда турбулентной) среде, которые актуальны (и приемлемы) для развития российских кооперативных практик в условиях существующих вызовов и угроз. Результаты. Обзорно-аналитическое исследование, результаты которого репрезентированы в данной статье, позволило (путем скрупулезного анализа достижений кооперативной теории за последние пять лет) сформулировать и научно обосновать основные компоненты нового (комплексного, междисциплинарного) подхода к развитию отечественной сельскохозяйственной кооперации в сложившемся институциональном и рыночном контексте, базовыми элементами которого являются: 1) учет особенностей социально-экономической и институциональной среды; 2) многофункциональность кооперативной деятельности; 3) специфика путей создания кооперативов в различных странах и сферах деятельности; 4) ограниченность традиционных и перспективность новых организационных моделей аграрных кооперативов. Научная новизна. В статье предложен подробный обзор зарубежных и российских исследований по различным аспектам сельскохозяйственной кооперации, отличающихся богатой историей и всесторонними дискуссиями, обоснована новая концепция развития современных аграрных кооперативов, сформулированы выводы, обладающие теоретической новизной и прикладной ценностью для использования в отечественной хозяйственной практике.

Ключевые слова: теория кооперации, сельскохозяйственный кооператив, социально-экономическая среда, институциональные и рыночные условия, вызовы и угрозы, литературный обзор.
\end{abstract}

Для цитирования: Головина С. Г., Смирнова Л. Н. Сельскохозяйственная кооперация в условиях новых вызовов и угроз: от теоретических дискуссий к хозяйственной практике // Аграрный вестник Урала. 2021. № 05 (208). C. 71-88. DOI: 10.32417/1997-4868-2021-208-05-71-88.

Дата поступления статьи: 27.03.2021, дата рецензирования: 08.04.2021, дата принятия: 26.04.2021.

Постановка проблемы (Introduction)

В то время как в различных странах мира кооперативная теория отмечается значимыми результатами исследований по вопросам функционирования сельскохозяйственных кооперативов в условиях современной среды, представляя их проблемы, пути преодоления и перспективы развития, все же можно констатировать, что имеющиеся теоретико-эмпирические достижения используются как в западной, так и отечественной кооперативной практике недостаточно широко, и в настоящее время на этот факт особо указывают и ученые, и политики, и специали- 
сты-аграрии. К примеру, в ходе одного из научных онлайн-семинаров (Современное состояние моделей сельскохозяйственной кооперации в России, 23 ноября 2020 г.) директор Центра агропродовольственной политики ИПЭИ РАНХиГС, доктор экономических наук Н. И. Шагайда подчеркивает, что предпринимаемые в настоящее время усилия относительно развития кооперативных процессов в отечественной хозяйственной практике (прежде всего аграрной) пока не коррелируют с имеющимися на сегодняшний день результатами.

Эту мысль подтверждают скрупулезные исследования условий и, конечно же, итогов деятельности сельскохозяйственных потребительских кооперативов в России, результаты которых (как будет описано далее) наглядно демонстрируют низкую эффективность функционирования большинства отечественных кооперативов и убедительно доказывают, что вместо экспансии своей деятельности многие созданные в последние годы сельскохозяйственные потребительские кооперативы существуют либо лишь в отчетности (формально), либо благодаря существенной государственной поддержке. Однако поиском возможностей развития кооперации в аграрной отрасли экономики различных стран занимаются многие известные ученые (как отечественные, так и зарубежные), а полученные ими результаты обладают эвристическим и прикладным потенциалом применительно не только к повышению (эволюционно достигнутого) уровня развития современной кооперации на Западе, но и к разрешению сложившейся негативной ситуации в деятельности отечественных кооперативов (особенно в условиях серьезных вызовов и угроз). В целом научная гипотеза исследования такова, что для успешной деятельности сельскохозяйственных кооперативов в сложившихся условиях среды необходима новая (комплексная, междисциплинарная) концептуальная модель развития кооперации, построение (и применение) которой возможно только на основе органичного синтеза достижений современной кооперативной теории, в связи с чем в представленной статье обзору, анализу и обобщению подлежали работы российских и зарубежных ученых, осуществляющих исследования в данной области знания в течение последних пяти лет (с 2016 г. по настоящее время).

В силу актуальности изучаемого феномена (сельскохозяйственная кооперация) в мировой кооперативной науке отмечаются весомые (уникальные) достижения, имеющие теоретическую и прикладную значимость, в то время как в рамках данного исследования пристальное внимание уделено главным образом тем изысканиям, которые могут послужить теоретической базой новой методологии развития российской сельскохозяйственной кооперации в условиях новых вызовов и угроз. Подчеркнем, что многие из них концентрируются на наиболее важных (для современной концептуализации аграрной кооперации) аспектах, в числе которых: 1) сопоставление сельскохозяйственных кооперативов с инвесторо-ориентированными фирмами (корпорациями), конкуренция между ними и варианты партнерских отношений [1-3]; 2) сложности, возникающие внутри сельскохозяйственных кооперативов в связи с гетерогенностью их членов [4], [5]; 3) уникальная роль традиционной кооперативной идентичности в экспансии кооперативной деятельности (в росте численности кооперативов и их членства, в увеличении занимаемой ими на рынках доли), в усилении социальной значимости кооперативных организаций и внедрении ими организационных и технологических инноваций [6], [7]; 4) совершенствование инструментов финансирования кооперативов путем трансформации их организационных моделей [8], [9]; 5) социализация деятельности аграрных кооперативов в целях устойчивого развития сельских территорий и сохранения сельских сообществ [10$12]$; 6) возможности развития кооперативного бизнеса в самых современных его формах [13], [14]; 7) особенности развития сельскохозяйственной кооперации в различных странах с учетом сформировавшейся в каждой из них особой социально-экономической и институциональной среды [15-17]. Научный интерес в рамках данного обзора представляют работы и российских ученых (М. П. Антоновой, Н. Г. Володиной, О. Б. Божкова, И. Н. Буздалова, А. А. Куракина, А. М. Никулина, А. В. Петрикова, В. А. Сарайкина, А. В. Соболева, И. В. Троцука, В. Я. Узуна, Н. И. Шагайды, Р. Г. Янбых и др.), обращающихся в своих исследованиях к специфике среды функционирования сельскохозяйственных кооперативов (в том числе в отдельных областях Российской Федерации и различных подотраслях сельского хозяйства), состоянию отечественной аграрной кооперации на различных этапах ее истории, характеристикам направлений и механизмов государственной поддержки кооперации на разных этапах институциональных преобразований отечественного АПК.

Отметим, что эволюция кооперативной мысли периодически находится в центре научных литературных обзоров, предпринимаемых западными коллегами, которые исследуют данную проблему уже не один десяток лет. В результате их многолетних кропотливых изысканий появились такие значимые публикации, как: 1) Torgerson R. E., Bruce J. R., Thomas W. G. Evolution of Cooperative Thought, Theory, and Purpose, 1997; 2) Cook M. L., Chaddad F. R., Illiopoulos C. Advances in Cooperative Theory since 1990: A Review of Agricultural Economics Literature, 2004; 3) Cook M. L., Grashuis J. Theory of Cooperatives: Recent Developments, 2018; 4) Grashuis J., Su Y. A Review of the Empirical Literature on Farmer Cooperatives: Performance, Ownership and Governance, Finance, and Member Attitude, 2018. И все же тщательное изучение работ ученых, исследующих преимущественно современное состояние сельскохозяйственной кооперации, позволяет сделать вывод о том, что, несмотря на имеющиеся описания эволюции кооперативной мысли (в том числе последние из них [18], [19]): 


\section{Agrarian Bulletin of the Urals No. 05 (208), 2021}

1) далеко не все достижения теории кооперации отражаются в имеющихся литературных обзорах;

2) как правило, западными коллегами анализируются научные труды, в которых исследуются проблемы, актуальные для США, Канады и стран Европейского Союза, касающиеся в первую очередь современных кооперативных организаций, прошедших длительный путь своей эволюции.

В данной работе (согласно поставленной цели) анализируются и обобщаются результаты исследований, которые, во-первых, проведены непосредственно в последние годы, во-вторых, осуществлены (в том числе) с участием российских ученых, в-третьих, наиболее актуальны (и приемлемы) для развития успешных кооперативных практик в сельском хозяйстве Российской Федерации в условиях новых вызовов и угроз.

Методология и методы исследования (Methods)

Для выполнения обозначенных в работе задач (определение потенциала современных исследований в области кооперативной теории для успешного развития кооперативных практик в России; спецификация научных результатов, обладающих эвристическим потенциалом для построения новой концепции кооперативного развития в условиях новых вызовов и угроз; выявление научных аспектов, требующих дополнительных исследований) в качестве ключевого метода обзора был выбран интегративный метод, эффективность которого (как доказывает Х. Снайдер [20, с. 335-336]) высока в том случае, когда цель ревью заключается не в полном охвате статей, опубликованных когда-либо по данному научному направлению, а в анализе существующих точек зрения для построения новой концептуальной модели (в данном случае - концепции развития сельскохозяйственной кооперации вообще и в специфических российских условиях в частности). Так как обзор литературы (по мнению авторитетных ученых [21, с. 2]) должен демонстрировать четко определенную стратегию выбора статей и изложенных в них научных идей, для отбора научных работ, подлежащих обзору в данном исследовании, использовались несколько критериев:

1) ограничение выборки научными изданиями за последние пять лет (с 2016 г. по настоящее время);

2) строгая спецификация обозначенной в публикациях тематики (аспекты деятельности сельскохозяйственных кооперативов, принятые в предлагаемой концепции их исследования в качестве базовых);

3) тщательная селекция журналов, в которых опубликованы результаты научных изысканий (предпочтение отдано журналам с высокими показателями уровня цитируемости, размещенным в международных базах данных).

Применение такого подхода в контексте данного исследования позволило изучить и критически проанализировать литературу из разных областей и исследовательских традиций для генерирования синтетической (междисциплинарной) методологии развития отечественных сельскохозяйственных кооперативов в сложившихся условиях среды.
Результаты (Results)

Как следует из результатов современных исследований, развитие сельскохозяйственных потребительских кооперативов в России базируется в основном на традиционном методологическом подходе, эвристический и прикладной потенциал которого ограничен в связи с кардинальными изменениями, происходящими в экономической, политической, социальной и институциональной среде. В то же время особенностью исследований последних лет (и в отечественной, и в западной науке) являются ориентация на эффективное функционирование аграрных кооперативов; акцент на результативность их деятельности с точки зрения многообразия выполняемых ими функций; нацеленность на прикладной характер исследований, результаты которых можно применять на практике. В связи с этим в предшествующих данному анализу исследованиях авторами статьи предложен используемый далее (для структурирования обзора) новый (комплексный, междисциплинарный) подход к исследованию сельскохозяйственной кооперации, базовыми элементами которого (исходя из предыдущих исследований авторов статьи) являются:

1) особенности среды (институциональной, рыночной) функционирования аграрных кооперативов;

2) многофункциональность деятельности современных сельскохозяйственных кооперативов;

3) идентификация кооператива как явления не стационарного и консервативного, а мобильного и адаптируемого (развивающегося по уникальной для каждой страны траектории);

4) ограниченные возможности внедрения в современную хозяйственную практику традиционного прототипа сельскохозяйственного кооператива, необходимость его трансформации в новые организационные модели [22].

Исследование кооперативной деятельности на базе перечисленных концептуальных постулатов позволяет, во-первых, разработать альтернативные варианты организационных моделей сельскохозяйственных кооперативов, каждая из которых обеспечивает им (в совершенно определенной окружающей среде, в том числе в условиях существующих (и потенциальных) вызовов и угроз, включая экологические, политические, биологические и другие) конкурентные преимущества путем внедрения в их внутреннюю структуру современных инструментов управления, контроля и финансирования; во-вторых, определить перспективные траектории дальнейшего развития сельскохозяйственной кооперации в сложившихся институциональных и рыночных условиях (с учетом возможных их флуктуаций); в-третьих, наметить направления государственной политики относительно сельскохозяйственных кооперативов, способствующие их успешному функционированию и как уникальных бизнес-единиц (действующих в интересах сельскохозяйственных производителей), и как особых артефактов, решающих многочисленные социальные проблемы сельских жителей и их сообществ. 
Обращаясь к более подробному изложению сформулированного (на основе синтеза теорий) подхода, начнем с того, что существенное место в теоретических исследованиях занимает концептуализация самого феномена «кооператив», являющегося загадкой для специалистов по кооперации еще со времен (если брать новейшую историю) И. Емельянова (Economic Theory of Cooperation, 1942 г.), рассматривающего кооператив не как разновидность фирмы, а как совокупность фирм. Современные ученые по-прежнему пытаются найти более подходящее определение столь сложной организации, отличающейся многомерной ролью ее членов (патрон, собственник, инвестор, управляющий) и многообразными (часто противостоящими друг другу) целями. В результате продолжающейся дискуссии кооператив и в настоящее время рассматривается учеными либо как продолжение фермерской организации, либо как коалиция независимых аграрных хозяйств, либо как независимая фирма [23, с. 132-133]. Существенным потенциалом в определении современной сущности кооператива обладает институциональная теория, базовые положения которой используются в исследованиях сельскохозяйственной кооперации и отечественными, и западными учеными (М. П. Антонова, С. Г. Головина, Р. Г. Янбых, А. В. Соболев, Дж. Биджман, А. Вольц, И. Мугвагва, Й. Нилссон, Г. Тон, Н. Хаддад, М. Т. Шрайри и др.) [15], [24-29].

Приступая к подробному обзору, рассмотрим в первую очередь вклад отдельных исследований в каждый из обозначенных элементов (всего четыре) предлагаемой концепции. Первый из них заключается в объективной (получаемой благодаря использованию различных современных методов и подходов) оценке институциональной среды, представленной институтами неформальными, формальными и рыночными. Что касается, например, институтов неформальных, то предпринятые теоретико-эмпирические исследования (экономические, социологические, психологические) позволяют вывести следующую (имеющую важное научно-практическое значение) аксиому: в какой бы организационной модели ни функционировал сельскохозяйственный кооператив (или в самой примитивной, не имеющей правовой оболочки, или в чрезвычайно современной, приближенной к обычной бизнес-корпорации), неформальная институциональная среда имеет решающее значение для его успешного развития [22]. При этом для кооперативных процессов (из широкого перечня неформальных институтов) особо значимы социальные ценности, такие как солидарность, равенство, доверие, ответственность [6], [30-32], не менее важны в эффективном развитии сельскохозяйственных кооперативов и некоторые характеристики их членов, а именно:

1) желание (потребность) быть вовлеченными в осуществляемую организацией деятельность [33];

2) открытость и готовность к коллективному (сетевому) взаимодействию [25];
3) стремление и, безусловно, возможности (способности, знания, умения) участвовать в процедурах демократического управления кооперативом [34];

4) позитивное отношение к кооперативным принципам в целом [35].

Подчеркнем, что сегодня современные крупные диверсифицированные кооперативные организации уделяют пристальное внимание гармоничным межличностным связям, интересам и предпочтениям своих членов или, по мнению ученых, «идиосинкразическому контексту жизненного мира отдельных членовфермеров» [5, с. 1075].

Основной исследовательский вывод, сформулированный в ходе скрупулезного изучения неформальной среды функционирования непосредственно отечественных сельскохозяйственных кооперативов, связан с выявлением и анализом причин отрицательных результатов их деятельности (небольших размеров, низкой эффективности, невысокой доли на рынках сельскохозяйственной продукции и услуг [27], [36], [37], [38]), причем в качестве таковых верифицированы:

1) негативный опыт кооперации в перестроечный период;

2) слабая предрасположенность сельскохозяйственных производителей к осуществлению трансакций на кооперативной основе;

3) низкий уровень доверия участников кооперации к партнерам и коллегам;

4) отсутствие у членов кооперативов опыта (как, впрочем, и желания) участия в демократическом управлении кооперативными организациями.

В связи с этим, по утверждению ученых, в условиях, когда создание сельскохозяйственных кооперативов в большинстве случаев инициируется «сверху» (как это наблюдается в отечественной хозяйственной практике), для государства важны не только специальные мероприятия, связанные с совершенствованием кооперативного законодательства и инструментов финансовой поддержки кооперативов, но и активные действия, направленные на улучшение доверия, формирование позитивного отношения к равенству, солидарности и взаимопомощи, то есть нацеленные на максимальное совершенствование неформальных институтов в направлении их релевантности кооперативному духу и кооперативной сути в целом [22]. Объединительные процессы на селе, генерируемые всевозможными консолидирующими мероприятиями, стимулируют в итоге улучшение неформальной среды функционирования кооперативов, создание неформальных институтов, являющихся субститутами формальных кооперативных организаций (в современном их понимании) и выполняющих важнейшие функции по поставке услуг и товаров в границах сельских территорий, в которых обычно не заинтересованы крупные коммерческие структуры [22], [25], [39]. Отметим, что в исследованиях относительно функционирования сельскохозяйственных кооперативов в тех странах, где они прошли длительный эволюци- 
онный путь и имеют в настоящее время неопровержимые доказательства их значимости, по-прежнему актуальны вопросы, касающиеся неформальных институтов (в частности социального капитала кооперативов), а их содержательные результаты все чаще появляются в академических изданиях мирового уровня [11], [40-42].

Не менее важное значение для развития сельскохозяйственной кооперации имеет формальная институциональная среда, включающая кооперативное законодательство, особые государственные программы поддержки сельхозкооперации, совершенствование которых также находится в центре внимания ученых. Так, И. Н. Буздалов подчеркивает значимость кооперативных законов в высокой динамике кооперативного развития [43], а А. В. Петриков, в свою очередь, аргументирует необходимость государственной поддержки сельского хозяйства в связи с новыми явлениями ${ }^{\wedge}$ :

1) в экономике (новые технологии в аграрном производстве);

2) в политике (санкционные ограничения или другие препятствующие свободному обмену обстоятельства, подобные локдауну во время пандемии COVID-19);

3) в экологии (изменение климата, другие экологические угрозы) [44].

Что касается исследований западных ученых, то таковые, безусловно, существуют, однако, как показывает глубокий анализ научных источников, многие из них, во-первых, акцентируют внимание на особенностях институциональной среды определенных стран (прежде всего стран с многолетней кооперативной историей, в которых развитие кооперативов происходит эволюционно и постепенно), во-вторых, не раскрывают противоречий между институтами формальными и неформальными. Российская же действительность отличается уникальными институциональными условиями, в которых из-за разобщенности формальных и неформальных институтов возникают серьезные (часто непреодолимые) барьеры, тормозящие развитие сельскохозяйственной кооперации в регионах Российской Федерации. Формальные институты в этой ситуации могут либо переживать существенные и адекватные по скорости изменения, способствуя развитию кооперативов, либо в совокупности с неформальными институтами, оставаясь консервативными, препятствовать их положительной эволюции. При этом формальные институты (как наиболее мобильные) способны посредством определенных нововведений в существующее законодательство и государственную политику нейтрализовать отрицательное воздействие институтов неформальных. Как следствие, создание соответствующей потребностям кооперативного развития формальной институциональной среды (гибкого законодательства, благоприятного бизнес-климата, эффективных государственных программ) является задачей как ученых и практиков (определение параметров сре- ды), так и политиков (легитимизация и внедрение в жизнь), причем необходимо учитывать всесторонне доказанный международным опытом факт, что государственная финансовая помощь признается сегодня довольно простым, но не самым эффективным направлением государственной поддержки. В итоге, сопоставляя данный вывод с общим подходом к содержанию формальных институтов, имеющих значение для развития отечественной кооперации, необходимо констатировать его неординарность и новизну, так как в ситуации постепенного и перманентного развития кооперативных практик важно, как правило, стабильное законодательство, с одной стороны, и финансовая помощь в кризисных (сложных) ситуациях - с другой [45]. Импортирование такого подхода из международного опыта в отечественную практику обычно признается закономерным и обоснованным, но, как показывают результаты изучения и анализа формальной среды, особенностей ее влияния на сельскохозяйственную кооперацию в России, подобная стратегия в отечественных условиях среды чаще всего проявляет свою несостоятельность [4].

Еще один существенный аспект первого элемента предлагаемого подхода, такой как учет рыночной составляющей среды (полученный путем применения разнообразных теоретических и эмпирических методов исследования), имеет в большей степени практическую значимость и прикладную направленность непосредственно в разрезе конкретных сельскохозяйственных рынков (рынки молока, мяса, зерна, картофеля, овощей и т. д.), причем в его реализации важны (как доказывают аналитические материалы научных источников) особенности ситуаций, складывающихся на распространенных рынках сельскохозяйственной продукции, на которых сельскохозяйственные кооперативы функционируют. Следует отметить, что многие ученые изучают деятельность кооперативов не в целом в отрасли (сельскохозяйственное производство), а в отдельных (конкретных) сферах аграрной деятельности [15], [41], [45-50]. Так, Й. Биджман, совершая глубокий экскурс в 130-летнюю историю голландских молочных кооперативов, обращается к институциональному объяснению их успеха (как особых институтов) в последние десятилетия, акцентируя внимание на таких их преимуществах, как экономия на масштабе, улучшение переговорных позиций, сокращение трансакционных издержек, совершенствование институционализации, институциональная поддержка [49]. В свою очередь, Л. Ли (вместе с коллегами), сосредоточивая научный интерес на функционировании китайских кооперативов в овощеводстве, причем в условиях высокой неопределенности (производственной, экологической, поведенческой), приходит к заключению, что по мере роста производственной неопределенности фермеры предпочитают членство в кооперативах и постоянные (контрактные) отношения с контрагентами и партнерами, а по мере усиления поведенческой неопределенности они обычно выбирают гибкие и вре́менные отношения, 
что обусловлено необходимостью быстрой адаптации к возникающим обстоятельствам [48]. Американские исследователи Т. Скевас и Дж. Грашуйс, фокусируясь на кооперативах по сбыту зерна, осуществляющих деятельность в границах Среднего Запада США (одного из четырех географических районов страны), убедительно доказывают факт влияния пространственных (территориальных) экстерналий на техническую эффективность соседствующих (расположенных в одной локации) зерновых кооперативов [49]. Коллектив ученых во главе с Т. Хуксом, останавливаясь на различных аспектах деятельности мясных кооперативов, убедительно подчеркивает, что индустриализация агропродовольственного сектора обусловливает различные неблагоприятные для фермеров последствия, такие как дисбаланс сил в технологической цепи, волатильность цен (и другие), преодоление которых возможно лишь путем кооперации [47].

Применительно к российской ситуации большое значение (по актуальности и содержательности) имеют исследования, обобщающие те научные материалы, в которых выявляются наиболее существенные особенности функционирования кооперативов в отдельных сферах сельскохозяйственного производства (в тех или иных областях Российской Федерации) [26], [38], [51], а полученные научно обоснованные выводы не только раскрывают специфику распространенных рынков сельскохозяйственной продукции (молока, мяса, зерна, картофеля, овощей и т. д.) относительно их расположенности к кооперативам, но и создают научную почву для построения прогнозов, которые (согласно методологическим постулатам представленной концепции) должны учитывать, вопервых, происходящие изменения в российском агропромышленном комплексе и на конкретных сельскохозяйственных рынках [52], [53]; во-вторых, возможные (адекватные этим изменениям) трансформации рыночных стратегий аграрных производителей и их кооперативов. В зависимости от этого прогнозируемые варианты будут различаться по таким параметрам, как:

1) занимаемые кооперативами ниши;

2) инкорпорируемые в их деятельность организационные модели;

3) оптимальные для развития сельскохозяйственных кооперативов инструменты государственной поддержки.

Второй важный компонент предлагаемой методологии касается такой уникальной особенности рассматриваемого феномена (сельскохозяйственный кооператив), как многофункциональность, новизна которого заключается в том, что, принимая во внимание популярную в современной науке концепцию многофункциональной деятельности отдельных хозяйственных субъектов, в ней:

1) учитывается территориальный аспект в оценке деятельности кооперативных организаций, их встроенность в сельские территории и сельский социум, что, по сути, идентифицируется многими исследо- вателями как предельно важное обстоятельство [26], [29], [54];

2) акцентируется внимание не только на экономической эффективности функционирования кооперативов (хотя и это имеет место), но и на эффективности социальной (вклад в решение социальных проблем) и экологической (нацеленность на экологическое благополучие сельских территорий) [55];

3) подчеркивается важность сервитизации в деятельности сельскохозяйственных кооперативов, что детерминирует для них новые возможности и в плане бизнеса, и в отношении социального предпринимательства [12], [56]. При этом четко прослеживается мысль, что сельскохозяйственный кооператив, функционируя оптимально, будучи экономически эффективным, является особым социально-экономическим феноменом, который:

1) создает условия для успешной деятельности аграрных хозяйств;

2) вызывает всевозможные положительные экстерналии, сопровождающие экономическую деятельность [12], [54].

В свою очередь, слабое (экономическое) развитие сельскохозяйственных кооперативов становится не только существенным препятствием для должного функционирования аграрных хозяйств (его членов), но и основной причиной появления многих отрицательных экстерналий. Таким образом, если отечественная наука подчеркивает значимость многофункциональной деятельности крупных аграрных организаций (как в свое время совхозы и колхозы, выполняющие всевозможные социальные функции на селе) [43], [55], [57], а западная - институтов взаимопомощи и солидарности (имеющих вековую историю) [12], [58], то предлагаемые выводы, полученные путем теоретического осмысления действительности и эмпирической апробации выдвинутых гипотез, предписывают широкий ряд различных миссий и разнообразных задач, связанных с решением многочисленных социальных и экологических проблем на селе, исключительно сельскохозяйственным кооперативам. Безусловно, в мировой кооперативной науке отмечается необходимость социализации кооперативного бизнеса [11], однако сложившаяся в России непростая ситуация (низкий уровень жизни селян, обезлюдение сельских территорий, набирающие остроту экологические риски), а сегодня еще и общемировые негативные обстоятельства, связанные с коронакризисом, обусловили повышенное внимание к многофункциональной природе исследуемого объекта и возможным положительным экстерналиям учета данного обстоятельства и в содержании государственной политики, и в организации кооперативных практик.

Третий (сформулированный на основе синтеза различных взглядов) элемент обозначенного научного подхода сводится к пониманию того, что кооперативы, несмотря на наличие в их функционировании традиционных (классических) основ, без которых невозможна идентификация этой формы (кооперати- 
ва) в качестве уникального феномена, действующего преимущественно в интересах своих членов, есть явление мобильное, а не стационарное. Современная же ситуация такова, что сельскохозяйственные кооперативы, как показывают мировой опыт и современные исследования, развиваются в разных странах по несколько отличным траекториям [59], следовательно, обязательный учет в процессе развития сельскохозяйственной кооперации (особенно в сложившемся рыночном и институциональном контексте) уникальных путей создания и последующей эволюции рассматриваемого феномена (аграрного кооператива) является важным концептуальным основанием предлагаемого подхода. Экскурс в историю (как кооперативной мысли, так и кооперативных практик) позволяет выделить два основных пути развития сельскохозяйственных кооперативов, первый из которых - эволюционный (континуальный), а второй дискретный (аффектированный). Так, эволюционное развитие следует представить в виде определенного алгоритма, а именно: создание по инициативе сельскохозяйственных производителей (или сельских жителей) простейших форм кооперации; постепенная адаптация организационного устройства этих объединений к условиям внешней среды; дальнейшее усложнение его структуры, в результате чего формируются, как правило, эффективные (современные) кооперативные организации. Что касается дискретного пути развития сельскохозяйственных кооперативов, отметим одно из важных его условий: если базовые организационные принципы кооператива (как организационной формы) соответствуют рыночной среде, формальным и неформальным институтам, то уже на этапе его создания появляется, как правило, жизнеспособная организационная структура, которая обладает существенной мотивацией, имеет широкие возможности для здоровой конкуренции, рационального взаимодействия с контрагентами и партнерами по бизнесу. В обратной ситуации возникают организации, жизнедеятельность которых возможна, но при условии значимой поддержки со стороны государства.

В данной научной плоскости чрезвычайно популярны работы, посвященные развитию сельхозкооперации в различных (в том числе по уровню социально-экономического развития) странах мира. В последние годы к таковым можно отнести исследования, научный фокус которых сосредоточен на вопросах развития сельскохозяйственной кооперации в странах с устойчивыми (и длительными) кооперативными традициями, таких как США [14], [49], Канада [60], Швеция [61], [62], а их главной особенностью является изучение таких актуальных для западных кооперативов (и не только для западных) проблем, как эффективность функционирования на отдельных агропродовольственных рынках, влияние различных аспектов менеджмента на успех деятельности кооперативов, сложности, возникающие в управлении кооперативом в связи с колоссальным ростом коо- перативных структур. Не менее содержательны с точки зрения полученных результатов (их теоретической и практической значимости) публикации об особенностях сельскохозяйственной кооперации в развивающихся странах и в странах с переходной экономикой, в числе которых Китай [50], [63], [64] Болгария [65], Румыния [66], Албания [31], Нигерия [67], Кения [34], Зимбабве [28], Марокко [15], Эфиопия [17]. Анализируя сформулированные учеными выводы, выделим наиболее значимые из них, в частности:

1) расширение кооперативной деятельности вверх и вниз по технологической (вертикальной) цепи усиливает благосостояние и кооператива, и его членов [50, с. 2274];

2) членство в кооперативах дает аграрным производителям определенные конкурентные преимущества (оптимальные размеры, доступ к финансовым ресурсам, возможность совместных инвестиций, дополнительные лоббирующие силы) [65, c. 505], [32];

3) выбор форм контрактных отношений и организация трансакций с продукцией и ресурсами зависят от состояния среды [28, с. 227-228];

4) большое значение для развития кооперации имеет благоприятная институциональная среда, в улучшении которой государство играет важную координирующую и нормотворческую роль [15, c. 247];

5) несмотря на очевидные положительные экстерналии, детерминирующие объединение фермеров в аграрные кооперативы, во многих бывших социалистических странах тем не менее наблюдается множество формальных и неформальных факторов, ограничивающих активное развитие кооперации [66].

Безусловно, исследования такого плана относительно уникальности траекторий развития отечественной кооперации имеют, во-первых, непосредственную практическую значимость для России (и других стран со схожими институциональными условиями и историческими реалиями); во-вторых, сугубо научную (теоретическую, фундаментальную) ценность, в том числе для обогащения кооперативной теории уникальным (отличным от эволюционного) опытом. В этом плане, конечно же, следует отметить статью Р. Янбых, В. Сарайкина, 3. Лермана «Cooperative Tradition in Russia: A Revival of Agricultural Service Cooperatives?» (2019г.), в которой авторы представляют результаты исследований о закономерностях развития отечественных сельскохозяйственных кооперативов в различные исторические эпохи:

1) со времен царской России до периода коллективизации (до 20-х годов прошлого столетия);

2) советский период развития России;

3) современный этап отечественной истории (начиная с 1990-х по настоящее время) [57]. 
Примерно в рамках такой же исторической периодизации анализирует развитие отечественной кооперации академик И. Н. Буздалов, причем, используя содержательный вербальный оборот «вековая драма», ученый обстоятельно характеризует кооперативную историю России 1917-2017 гг. [43]. Целесообразно также выделить работы исследователей, посвященные условиям (факторам) эффективной деятельности сельскохозяйственных кооперативов [36], [68], современным проблемам развития кооперации в отдельных областях сельскохозяйственной деятельности (к примеру, в молочной отрасли) [46], прогнозированию дальнейшего (перспективного) развития кооперации на основе ее исторического опыта [55].

Выделяя следующий (четвертый) компонент усовершенствованного концептуального подхода, подчеркнем, что в его основе заложены, во-первых, конкретные возможности и серьезные ограничения применения в современных условиях классического (традиционного) устройства кооператива, во-вторых, необходимость инкорпорации в отечественную практику новых организационных моделей кооперативов. Теоретико-эмпирические исследования, выполняемые на протяжении последних нескольких лет, аргументированно доказывают важность этого компонента, идентифицируя в качестве главных факторов (особых обстоятельств) недостаточной эффективности деятельности отечественных аграрных кооперативов и, как следствие, низкой результативности развития российской аграрной кооперации в целом:

1) сложности в реализации традиционной кооперативной модели в отечественных условиях среды;

2) невозможность внедрения в отечественную хозяйственную практику новых предпринимательских моделей аграрной кооперации [69].

Реальность такова, что инкорпорируемая в отечественную среду (традиционная) организационная модель кооператива вступает в конфронтацию со сложившимися формальными и неформальными институтами, обусловливая неэффективную деятельность самих кооперативных структур в первую очередь тем, что не способна реализовать ключевой для данной организационной модели эффект масштаба. Неизбежным следствием подобной ситуации в странах Запада (США, Канада, Англия, Швеция и др.) является ослабление традиционных кооперативных принципов и постепенное смещение кооперативной деятельности в сторону предпринимательской организационной конструкции посредством:

1) введения в кооперативную практику новшеств, предполагающих:

a) механизм принятия решений и распределения прибыли в соответствии с объемом вложений в кооператив;

б) доходы на инвестиционные вложения, осуществляемые не только членами кооператива, но и внешними инвесторами;

2) эмиссии внутренних и внешних ценных бумаг, позволяющих привлекать достаточные финансовые ресурсы членов кооператива, внешних инвесторов;
3) индивидуализации всех основных аспектов деятельности кооператива (собственность, управление, контроль, но при условии сохранения некоторых базовых (традиционных) принципов) в целях повышения эффективности функционирования сельскохозяйственных кооперативов.

Подобные модификации отмечены во многих работах западных ученых, таких, к примеру, как серия публикаций Дж. Грашииса и М. Кука («Farmer Cooperatives as Systems of Attributes: An Analysis of Ownership and Investment Complementarities» (2017 г.), «An Examination of New Generation Cooperatives in the Upper Midwest: Successes, Failures, and Limitations» (2018 г.), «An Exploratory Study of Ownership and Governance Interrelationships in Traditional and Hybrid Farmer Cooperatives» (2018 г.), «A Structural Equation Model of Cooperative Member Satisfaction and Longterm Commitment» (2019 г.) [3], [13], [14], [29]), в которых авторы, во-первых, обосновывают гибридную сущность различных атрибутов современного сельскохозяйственного кооператива [14], [23]; во-вторых, устанавливают путем сложного эмпирического анализа (Structural Equation Model) взаимозависимость между различными характеристиками деятельности кооператива, в числе которых доверие, удовлетворенность, общие ценности, эмоциональная приверженность (причем как в мелких, так и в крупных кооперативах с гетерогенными взглядами членов на кооперативную деятельность) [4]; в-третьих, исследуют траектории развития кооперативов нового поколения (new generation cooperatives), активно создаваемых в американской аграрной экономике, начиная с 90-х годов прошлого столетия 14]. В свою очередь, проблемы, связанные непосредственно с управлением традиционно организованными крупными кооперативами, имеющими многочисленный и разнородный состав членов, осуществляющими сложные трансакции, раскрывает в своей статье «Governance Costs and the Problems of Large Traditional Co-Operatives» (2018 г.) Й. Нилссон, заключая, что деятельность таких кооперативов сопровождается ростом затрат на управление (трудно координировать большую и разнородную группу членов такого кооператива), а коллективный капитал (распределение которого не соответствует рыночным законам), в сущности, не используется оптимально, так как члены кооператива, с одной стороны, несут высокие затраты на принятие риска, а с другой - не получают полной остаточной прибыли [62].

Обращаясь к изменениям, происходящим в современных кооперативах, необходимо иметь в виду, что отмеченные выше (как и другие) внутренние усовершенствования связаны не только с сугубо технологическими новшествами (как следствие, с увеличением размеров кооперативов, сложностями в совершении трансакций, необходимостью привлечения больших объемов финансового капитала), но и с изменениями качества социального капитала кооператива по мере его развития (при переходе от одной фазы к другой). 
Agrarian Bulletin of the Urals No. 05 (208), 2021

Важность данного обстоятельства аргументировано анализируется в публикации В. Дэна, Г. Хендрикса, К. Ляна «Internal Social Capital and the Life Cycle of Agricultural Cooperatives» (2021 г.), в которой авторы утверждают, что «если стратегически не поддерживать и не развивать социальный капитал, сравнительное преимущество кооперативной формы бизнеса может исчезнуть» [40]. Одной из форм такой поддержки является адаптация организационной модели кооператива к трансформациям, неизбежно происходящим с социальным капиталом. Уместно отметить, что особенности функционирования кооператива на различных фазах жизненного цикла (всего их пять) освещаются и в ряде работ М. Кука, например, в статье "A Life Cycle Explanation of Cooperative Longevity", опубликованной в 2018 г., в которой ученый с позиции междисциплинарного подхода подробно раскрывает переживаемые кооперативом организационные изменения [70].

В то же время важно понимать, что кооперативные ценности (как и все элементы кооперативной организационной структуры) должны совершенствоваться, особенно в те периоды, когда существенно меняется окружающая среда. В российской же действительности в условиях, когда кооперативные структуры (как на этапе создания, так и в первые годы функционирования) отличаются небольшими размерами, недостатком капитала, ограниченными возможностями к внедрению современных технологий, низкой конкурентоспособностью, дальнейшее культивирование сугубо традиционных принципов (открытого членства, неограниченных трансакций, привлекательной идеологии коллективизма) в существенной мере ограничивает стремительное расширение бизнеса и фактически не обеспечивает его участников конкурентными преимуществами, вследствие чего отмечаются:

1) низкая эффективность в деятельности кооперативных организаций;

2) функционирование кооперативов благодаря (в основном) государственной поддержке [69].

В целом, определение места традиционных кооперативных организаций в современных условиях среды и перспективные варианты либо их сохранения, либо существенной модификации - значимый результат использования учеными подхода, отличающегося от общепринятого (консервативного) отношения к традиционной кооперативной идентичности [36], [71]. Резюме таких публикаций: кооперативы традиционного типа необходимы и значимы (причем на любом этапе развития общества), однако их успешная работа, как показывает практика, зависит от определенных обстоятельств [71]. Ярким примером такого заключения служит активное появление кооперативов в сельских районах различных стран мира вследствие:

1) их удаленности от урбанизированных центров;

2) неблагоприятных демографических явлений (снижение численности сельского населения);
3) сокращения в селах числа крупных сетевых организаций (поставляющих различные услуги и товары);

4) негативных эффектов пандемии COVID-19 (и других ухудшающих сельскую жизнь условий) [22].

Раскрывая прикладной потенциал излагаемой в данном обзоре концепции, подчеркнем, что труды известных в области кооперативной теории ученых посвящены непосредственно проблемам адаптации сельскохозяйственных кооперативов к рыночной среде, в том числе посредством некоторых изменений и в организационных моделях, и в стратегиях. Так, исследование стратегической адаптации фермерских кооперативов в ответ на различные внешние события (консолидация отрасли, сегментация потребителей, снижение и волатильность цен, изменение политики) предпринято Дж. Грашиисом, неоднократно упомянутым в данном обзоре [71]. В других эпизодах научных исследований отмечается индивидуальность и локальность применяемых стратегий и внедряемых организационных моделей, и в этом отношении следует отметить (как наиболее продуктивные) работы Й. Нилссона, первые из которых появились в 1990-е годы ("New Generation Farmer Co-Ops", 1997; "The Emergence of New Organizational Models for Agricultural Cooperatives", 1998; "Co-Operative Organisational Models as Reflections of The Business Environment", 1999), четко обозначив отличительные особенности кооперативов предпринимательского типа от их традиционных аналогов. Сегодня разработанная им теория используется, к примеру, в ходе анализа структуры управления в крупнейших сельскохозяйственных кооперативах Швеции (отличающихся крупными размерами, большим объемом бизнес-операций, разнородным членским составом), результаты которого демонстрируют то, как совершенствование кооперативных принципов способствует не только повышению конкурентоспособности кооперативов, но и росту удовлетворенности их членов [16]. Не менее интересны в плане сравнительного описания двух типов кооперативов (предпринимательского и традиционного) публикации М. Кука и его коллег (уже отмеченные в данной работе), причем как более ранние, так и сегодняшние [3], [14], [23]. В целом же можно констатировать, что выводы, полученные на основе изучения вышеобозначенных научных трудов по проблеме современных моделей кооперативных организаций, обладают практической значимостью для российских кооперативных практик, а обобщающие результаты практического опыта развития кооперативов в зарубежных странах (в совокупности с глубоким анализом других наиболее актуальных теоретических материалов по вопросам организационных моделей кооперации) и аналитические материалы, касающиеся эффективности кооперативных процессов в российской аграрной экономике, позволяют специфицировать наиболее перспективные модели предпринимательского кооператива, которые (по организационным особенностям) находятся между 
двумя теоретическими конструкциями, в частности, традиционным кооперативом и инвесторо-ориентированной фирмой [22], [72]. Выделяя (по результатам исследований) три теоретические организационные модели кооперативной деятельности, специфицированные как предпринимательские кооперативы первого, второго и третьего типа [72], можно резюмировать, что инкорпорация в деятельность сельскохозяйственных кооперативов новых организационных принципов включает несколько ступеней сложного (комплексного) алгоритма, таких как:

1) разработка альтернативных вариантов организационной трансформации;

2) уточнение различных организационных аспектов;

3) их детальная апробация, которая, по сути, невозможна без использования достижений современной кооперативной науки (привлечения ученых), а также без участия политиков (влияющих на контент формальной институциональной среды развития сельскохозяйственных потребительских кооперативов) и активной вовлеченности в данный процесс практиков (участников кооперации).

Обсуждение и выводы (Discussion and Conclusion)

Обобщающие научные материалы, полученные в ходе досконального изучения современных достижений кооперативной науки и деятельности отечественных и западных сельскохозяйственных потребительских кооперативов, имеют как научную, так и прикладную значимость. Основная научная новизна представлена усовершенствованной концептуализацией развития сельскохозяйственных кооперативов в сложившемся институциональном и рыночном контексте, прикладная - сформулированными практико-ориентированными выводами, систематизированными в русле нескольких концептуальных компонентов и представленными в виде научно-практических рекомендаций (заслуживают внимание тех экономических и политических стейкхолдеров, которые заинтересованы в успешном функционировании сельскохозяйственных потребительских кооперативов во флуктуирующих условиях среды) [4].

1. В то время как, с одной стороны, обычную эволюцию кооперативных практик можно ассоциировать с плавным их переходом от одного этапа к другому (в связи с чем отмечаются развитие на фоне особой сельской жизни, в границах уникальных сельских сообществ и неформальных институтов различных институтов взаимопомощи, сотрудничества, взаимной выручки; формирование большого числа мелких кооперативов в различных подотраслях сельского хозяйства и сферах сельской жизнедеятельности; рост разнообразия кооперативных организаций, их формальных и неформальных объединений; все более тщательная институционализация деятельности кооперативов; рост численности членов кооперативов (увеличение размеров кооперативов), сокращение числа кооперативных организаций; изменение организационной структуры кооперативов в направлении бизнес-ориентированных организаций; повышение экономической эффективности их деятельности и конкурентоспособности), а с другой - нельзя исключать ситуацию, когда такой путь кооперативного развития невозможен (конкурентоспособными могут быть лишь крупные кооперативные структуры, соответствующие по своим размерам и ресурсному потенциалу другим организационным формам бизнеса), колоссальное значение имеют:

1) содержание неформальной среды;

2) формальные условия создания, становления и развития кооперативов;

3) рыночная ситуация в сферах деятельности кооперативов.

При этом в качестве важного направления государственной политики по развитию сельскохозяйственной кооперации в современных условиях среды (даже в сравнении с сегодняшней существенной финансовой помощью сельскохозяйственным кооперативам) следует специфицировать поддержку различных (в том числе самых простых) форм сотрудничества и взаимопомощи (а не только кооперативов как таковых).

2. В связи с предельной значимостью благоприятной формальной среды для благополучия кооперативов (особенно если неформальная среда не совсем мобильна и благоприятна) разработка современного кооперативного законодательства, предоставляющего кооператорам широкий выбор возможностей спецификации прав собственности, моделей управления, применяемых стратегий, - важнейшее условие эффективной деятельности сельскохозяйственных кооперативов как уникальных бизнес-единиц и успешного развития аграрной отрасли в целом, а разумная государственная политика по поддержке выполнения кооперативами соответствующего сегодняшней ситуации спектра социальных и экологических функций (особенно в условиях существующих вызовов и угроз) - ключевая детерминанта устойчивого развития сельских территорий и сельских сообществ.

3. Идентификация и научное обоснование целесообразности функционирования сельскохозяйственных кооперативов в современных (предпринимательских) организационных моделях обусловливает совершенно иную стратегию поведения государственных структур в ходе инициации создания кооперативов в различных сферах аграрного производства и сельской деятельности. Поддержка теми или иными структурами предпринимательских организационных моделей кооперативов, как и традиционных их видов (что определяется именно релевантностью организационного устройства сельскохозяйственных кооперативов и окружающей среды на каждом этапе их эволюции), должна осуществляться, во-первых, в различных формах (не только финансовой), во-вторых, в оптимальном направлении (инициация же сугубо традиционных кооперативных феноменов не приносит (да и не принесет) ожидаемых всеми результатов даже при колоссальных финансовых затратах). Ключевая идея, 


\section{Agrarian Bulletin of the Urals No. 05 (208), 2021}

сформулированная в ходе обзорно-аналитического исследования научных материалов, заключается в том, что только гармоничный симбиоз результатов, полученных в ходе широких (междисциплинарных) исследований сельскохозяйственной кооперации (как теоретических, так и эмпирических), может служить фундаментальной и прикладной базой эффективного (и с точки зрения аграрных производителей, и с позиции сельских сообществ) функционирования сель- скохозяйственных потребительских кооперативов в условиях меняющихся общественных приоритетов, непредсказуемых флуктуаций среды, новых вызовов и угроз.

\section{Благодарности (Acknowledgements)}

Исследование выполнено при финансовой поддержке РФФИ в рамках научного проекта № 20-11050167.

\section{Библиографический список}

1. Illiopoulos C., Cook M. L., Chadad F. Agricultural Cooperatives in Netchains // Journal of Chain and Network Science. 2016. Vol. 16 (1). Pp. 1-6. DOI: 10.3920/JCNS2016.x003.

2. Liang Q., Hendrikse G. Pooling and the Yardsticks Effect of Cooperatives // Agricultural Systems. 2016. Vol. 143. Pp. 97-105. DOI: 10.1016/j.agsy.2015.12.004.

3. Ménard C. Organization and Governance in the Agrifood Sector: How Can We Capture Their Variety? // Agribusiness. 2018. Vol. 34 (1). Pp. 142-160. DOI: 10.1002/agr.21539.

4. Grashuis J., Cook M. L. A Structural Equation Model of Cooperative Member Satisfaction and Long-term Commitment // International Food and Agribusiness Management Association. 2019. Vol. 22 (2). Pp. 247-263. DOI: 10.22434/IFAMR2018.0101.

5. Iliopoulos C., Valentinov V. Member Preference Heterogeneity and Systemlifeworld Dichotomy in Cooperatives: An Exploratory Case Study // Journal of Organizational Change. Management. 2017. Vol. 30 (7). Pp. 1063-1080. DOI: 10.1108/JOCM-12-2016-0262.

6. Соболев А. В., Брилон А. В., Ермилов М. М. Кооперация в фокусе исследователей: кооперативная модель, поведение и стратегия // Фундаментальные и прикладные исследования кооперативного сектора экономики. 2019. № 3. С. 31-42.

7. Puusa A., Hokkila K., Varis A. Individuality vs. Communality - A New Dual Role of Co-operatives? // Journal of Co-operative Organization and Management. 2016. Vol. 4 (1). Pp. 22-30. DOI: 10.1016/j.jcom.2016.02.002.

8. Briggeman B. C., Jacobs K. L., Kenkel P., Mckee G. J. Current Trends in Cooperative Finance // Agricultural Finance Review. 2016. Vol. 76 (3). Pp. 402-410. DOI: 10.1108/AFR-04-2016-0034.

9. Grashuis J. A Quantile Regression Analysis of Farmer Cooperative Performance // Agricultural Finance Review. 2018. Vol. 78 (1). Pp. 65-82. DOI: 10.1108/AFR-05-2017-0031.

10. Bijman J., Muradian R., Schuurman J. (eds.) Cooperatives, Economic Democratization and Rural Development. Edward Elgar Pub. Ltd., Cheltenham, UK, 2016. 310 p.

11. Kustepeli Y., Gulcan Y., Yercan M. et al. The Role of Agricultural Development Cooperatives in Establishing Social Capital // The Annals of Regional Science. Published online 20 January 2020. DOI: 10.1007/s00168-01900965-4.

12. Roth S., Valentinov V., Kaivo-oja J., Dana L.-A. Multifunctional Organisation Models: A Systems - Theoretical Framework for New Venture Discovery and Creation // Journal of Organizational Change Management. 2018. Vol. 31 (7). Pp. 1383-1400. DOI: 10.1108/JOCM-05-2018-0113.

13. Grashuis J. An Exploratory Study of Ownership and Governance Interrelationships in Traditional and Hybrid Farmer Cooperatives // Managerial and Decision Economics. 2018. Vol. 39 (6). Pp. 664-673. DOI: 10.1002/mde.2936.

14. Grashuis J., Cook M. L. An Examination of New Generation Cooperatives in the Upper Midwest: Successes, Failures, and Limitations // Annals of Public and Cooperative Economics. 2018. Vol. 89(4). Pp. 623-644. DOI: 10.1111/apce.12211.

15. Haddad N. O., Ton G., Sraïri M. T., Bijman J. Organisational Challenges of Moroccan Dairy Cooperatives and the Institutional Environment // International Journal on Food System Dynamics. 2017. Vol. 8 (3). Pp. 236-249. DOI: 10.18461/ijfsd.v8i3.835.

16. Hakelius K., Nilsson J. The Logic behind the Internal Governance of Sweden's Largest Agricultural Cooperatives // Sustainability. 2020. Vol. 12 (21). P. 9073. DOI: 10.3390/su12219073.

17. Royer A., Bijman J., Abebe G. K. Cooperatives, Partnerships and the Challenges of Quality Upgrading: A Case Study from Ethiopia // Journal of Co-operatives Organization and Management. 2017. Vol. 5 (1). Pp. 48-55. DOI: 10.1016/j.jcom.2017.04.001.

18. Cook M. L., Grashuis J. Theory of Cooperatives: Recent Developments. In: Routledge Handbook of Agricultural Economics. New York, NY: Routledge, 2018. Pp. 372-392.

19. Grashuis J., Su Y.A Review of the Empirical Literature on Farmer Cooperatives: Performance, Ownership and Governance, Finance, and Member Attitude // Annals of Public and Cooperative Economics. 2018. Vol. 90 (1). Pp. 77-102. DOI: 10.1111/ apce. 12205 .

20. Snyder H. Literature Review as A Research Methodology: An Overview and Guidelines // Journal of Business Research. 2019. Vol. 104. Pp. 333-339. DOI: 10.1016/j.jbusres.2019.07.039. 
21. Palmatier R. W., Houston M. B., Hulland J. Review Articles: Purpose, Process, and Structure // Journal of the Academy of Marketing Science. 2018. Vol. 46. Pp. 1-5. DOI: 10.1007/s11747-017-0563-4.

22. Головина С. Г., Смирнова Л. Н. Научно-практические рекомендации по использованию международного опыта развития сельскохозяйственной кооперации в отечественной хозяйственной практике. Курган: Изд-во КГСХА, 2020. $273 \mathrm{c}$.

23. Grashuis J., Cook M. L. Farmer Cooperatives as Systems of Attributes: An Analysis of Ownership and Investment Complementarities // Hendrikse G. W. J., Cliquet G., Ehrmann T., Windsperger J. (eds.) Management and Governance of Networks: Franchising, Cooperatives, and Strategic Alliances. Springer International Publishing: New York (NY, USA). 2017. Pp. 131-147. DOI: 10.1007/978-3-319-57276-5_8.

24. Антонова М. П., Потапова А. А. Создание кооперативов по принципу top-down: потенциальные ошибки // Экономическое развитие России. 2019. Т. 26. № 7. С. 56-64.

25. Сарайкин В. А., Янбых Р. Г. Анализ устойчивости кооперативной формы хозяйствования аграрного сектора России в контексте институциональной теории фирмы // Вестник Санкт-Петербургского университета. Экономика. 2019. Т. 35. Вып. 2. C. 251-268. DOI: 10.21638/spbu05.2019.204.

26. Соболев А. В., Пахомов В. М., Рыкалин А. С. Сельскохозяйственные кооперативы: институциональный и региональный подтекст // Фундаментальные и прикладные исследования кооперативного сектора экономики. 2020. № 1. C. 90-100.

27. Golovina S., Antonova M., Abilova E. Assessment of Agricultural Cooperatives' Performance in Russia: The Case of the Kurgan Region // Advances in Social Science, Education and Humanities Research. 2020. Vol. 392. Pp. 370-376. DOI: 10.2991/assehr.k.200113.077.

28. Mugwagwa I., Bijman J., Trienekens J. Typology of Contract Farming Arrangements: A Transaction Cost Perspective // Agricultural Economics Research, Policy and Practice in Southern Africa. 2020. Vol. 59 (2). Pp. 169187. DOI: $10.1080 / 03031853.2020 .1731561$.

29. Wolz A. Golovina S., Nilsson J., Hess S. Reviewing Changing Institutional Conditions for Private Farming in Russia // Outlook on Agriculture. 2016. Vol. 45 (2). Pp. 111-116. DOI: 10.1177/0030727016651214.

30. Hakelius K., Hansson H. Members' Attitudes towards Cooperatives and Their Perception of Agency Problems // International Food and Agribusiness Management Association. 2016. Vol. 19 (4). Pp. 1-14. DOI: 10.22434/ IFAMR2015.0219.

31. Sokoli O., Doluschitz R. Cooperative Evolvement through Political Era / Epoch: Albanian's Case and Comparisons // Economics of Agriculture. 2019. Vol. 66 (1). Pp. 189-204. DOI: 10.5937/ekoPolj1901189S.

32. Yu L., Nilsson J. Social Capital and Financial Capital in Chinese Cooperatives // Sustainability. 2019. No. 11 (8). P. 2415. DOI: 10.3390/su11082415.

33. Golovina S., Hess S., Nilsson J., Wolz A. Networking among Russian Farmers and their Prospects for Success // Post-Communist Economies. 2019. Vol. 31 (4). Pp. 48-499. DOI: 10.1080/14631377.2018.1537737.

34. Mwambi M., Bijman J., Mshenga P. Which Type of Producer Organization is (More) Inclusive? Dynamics of Farmers' Membership and Participation in the Decision-Making Process // Annals of Public and Cooperative Economics. 2020. Vol. 91 (2). Pp. 213-236. DOI: 10.1111/apce.12269.

35. Kontogeorgos A., Sergaki P., Chatzitheodoridis F. An Assessment of New Farmers' Perceptions about Agricultural Cooperatives // Journal of Developmental Entrepreneurship. 2017. Vol. 22 (1). Pp. 1750003(1)-1750003(13). DOI: 10.1142/S1084946717500030.

36. Сарайкин В. А., Янбых Р. Г. Направления совершенствования организации и эффективного развития кооперации // АПК: Экономика, Управление. 2017. № 6. С. 40-47.

37. Medvedeva T. Assessment of Solvency and Financial Stability of Agricultural Consumer Cooperatives // Advances in Social Science, Education and Humanities Research. 2019. Vol. 392. Pp. 331-335. DOI: 10.2991/ assehr.k.200113.069.

38. Kurakin A., Visser O. Post-Socialist Agricultural Cooperatives in Russia: A Case Study of Top-Down Cooperatives in the Belgorod Region // Post-Communist Economies. 2017. Vol. 29 (2). Pp. 158-181. DOI: 10.1080/14631377.2016.1267974.

39. Божков О. Б., Никулин А. М., Полещук И. К. Сельская кооперация в Северном Нечерноземье: официальные и неформальные практики // Вестник российского университета дружбы народов. Серия: социология. 2020. T. 20. № 4. C. 889-904. DOI: 10.22363/2313-2272-2020-20-4-889-904.

40. Deng W., Hendrikse G., Liang Q. Internal Social Capital and the Life Cycle of Agricultural Cooperatives // Journal of Evolutionary Economics. 2021. Vol. 31 (1). Pp. 1-23. DOI: 10.1007/s00191-020-00690-8.

41. Feng L., Friis A., Nilsson J. Social Capital among Members in Grain Marketing Cooperatives of Different Sizes // Agribusiness. 2016. Vol. 32 (1). Pp. 113-126. DOI: 10.1002/agr.21427.

42. Liang Q., Lu H., Deng W. Between Social Capital and Formal Governance in Farmer Cooperatives: Evidence from China // Outlook on Agriculture. 2018. Vol. 47 (1). Pp. 196-203. DOI: 10.1177/0030727018778603.

43. Буздалов И. Н. Вековая драма российской кооперации (1917-2017) // Агропродовольственная политика России. 2017. № 5 (65). С. 2-10. 
44. Петриков А. В. Адаптация агропродовольственного сектора к постпандемической реальности // Научные труды Вольного экономического общества России. 2020. Т. 223. № 3. C. 99-105. DOI: 10.38197/2072-20602020-223-3-99-105.

45. Bijman J. Exploring the Sustainability of the Cooperative Model in Dairy: The Case of the Netherlands // Sustainability. 2018. Vol. 10 (7). P. 2498. DOI: 10.3390/su10072498.

46. Янбых Р. Г., Гатаулина Е. А. Оценка изменения потенциала сельскохозяйственной потребительской кооперации в молочной отрасли за десять лет (2006-2016 годы) // Фундаментальные и прикладные исследования кооперативного сектора экономики. 2019. № 1. С. 19-25.

47. Hooks T., McCarthy O., Power C. Macken-Walsh A. A Co-operative Business Approach in a Values-based Supply Chain: A Case Study of a Beef Co-operative // Journal of Co-operative Organization and Management. 2017. Vol. 5. Iss. 2. Pp. 65-72. DOI: 10.1016/j.jcom.2017.10.001.

48. Li L., Guo H., Bijman J., Heerink N. The Influence of Uncertainty on the Choice of Business Relationships: The Case of Vegetable Farmers in China // Agribusiness. 2018. Vol. 34. Pp. 597-615. DOI: 10.1002/agr.21540.

49. Skevas T., Grashuis J. Technical Efficiency and Spatial Spillovers: Evidence From Grain Marketing Cooperatives in the Us Midwest // Agribusiness. 2020. Vol. 36. Pp. 111-126. DOI: 10.1002/agr.21617.

50. Zhong Z., Zhang C., Jia F., Bijman J. Vertical Coordination and Cooperative Member Benefits: Case Studies of Four Dairy Farmers' Cooperatives in China // Journal of Cleaner Production 2018. Vol. 172. Pp. 2266-2277. DOI: 10.1016/j. jclepro.2017.11.184.

51. Loretts E., Golovina S., Smirnova L. Functioning Field of Farm Enterprises in Russia: Uncertainty and Risks. Proceedings of the International Scientific and Practical Conference «Digital Agriculture - Development Strategy» (ISPC 2019) // Advances in Intelligent Systems Research. 2019. Vol. 167. Pp. 470-475. DOI: 10.2991/ispc19.2019.106.

52. Узун В. Я., Шагайда Н. И. Оценка влияния институциональных и структурных изменений на развитие аграрного сектора России // Вопросы экономики. 2019. № 4. С. 39-58. DOI: 10.32609/0042-8736-2019-4-39-58.

53. Yanbykh R., Saraikin V., Lerman Z. Changes in Russia's Agrarian Structure: What Can We Learn from Agricultural Census? // Russian Journal of Economics. 2020. No. 6. Pp. 26-41. DOI: 10.32609/j.ruje.6.49746.

54. Головина С. Г., Лоретц Е. Е., Смирнова Л.Н. Многофункциональность деятельности сельскохозяйственных кооперативов // Аграрный вестник Урала. № 3. 2019. С. 58-63. DOI: 10.32417/article_5ce40514 $1 \mathrm{f} 3952.34454910$.

55. Sobolev A., Kurakin A., Pakhomov V., Trotsuk I. Cooperation in Rural Russia: Past, Present and Future // Universe of Russia. 2018. Vol. 27 (1). Pp. 65-89. DOI: 10.17323/1811-038X-2018-27-1-65-89.

56. Šumylè D., Ribašauskienė E. Servitization of Lithuanian Agricultural Cooperatives // Management Theory and Studies for Rural Business and Infrastructure Development. 2017. Vol. 39 (4). Pp. 510-523. DOI: 10.15544/ mts.2017.35.

57. Yanbykh R., Saraikin V., Lerman Z. Cooperative Tradition in Russia: A Revival of Agricultural Service Cooperatives? // Post-Communist Economies. 2019. Vol. 31 (6). Pp. 751-771. DOI: 10.1080/14631377.2019.1607439.

58. Iliopoulos C., Valentinov V. Cooperative Longevity: Why Are So Many Cooperatives So Successful? // Sustainability. 2018. Vol. 10 (10). P. 3449. DOI: 10.3390/su10103449.

59. Nilsson J., Golovina S., Hess S., Wolz A. Governance of Production Cooperatives in Russian Agriculture // Annals of Public and Cooperative Economics. 2016. Vol. 87 (4). Pp. 541-562. DOI: 10.1111/apce.12123.

60. Cameron G., Rosado F. R. P., Mederos D. D. D. Agricultural Co-Operatives in Canada and Cuba: Trends, Prospects and Ways Forward // Environment, Development and Sustainability. 2020. No. 22. Pp. 643-660.

61. Morfi C., Nilsson J., Österberg H. Why Farmers Involve Themselves in Co-Operative District Councils // Annals of Public and Cooperative Economics. 2018. Vol. 89 (4). Pp. 581-598. DOI: 10.1111/apce.12206.

62. Nilsson J. Governance Costs and the Problems of Large Traditional Co-Operatives // Outlook on Agriculture. 2018. Vol. 47 (2). Pp. 87-92. DOI: 10.1177/0030727018761175.

63. Yu L., Huang W. Non-Economic Societal Impact or Economic Revenue? A Performance and Efficiency Analysis of Farmer Cooperatives in China // Journal of Rural Studies. 2020. Vol. 80. Pp. 123-134. DOI: 10.1016/j. jrurstud.2020.08.010.

64. Zhang S., Wolz A. Ding Y. Is There a Role for Agricultural Production Cooperatives in Agricultural Development? Evidence from China // Outlook on Agriculture. 2020. Vol. 49 (3). Pp. 256-263. DOI: 10.1177/0030727020913283.

65. Zaimova D., Doitchinova J., Zheliazkov G. Transition and Agricultural Cooperatives in Bulgaria // CBU International Conference Proceedings. 2017. Vol. 5. Pp. 499-507. DOI: 10.12955/cbup.v5.974.

66. Wolz A., Mollers J., Micu M. M. Options for Agricultural Service Cooperatives in a Postsocialist Economy: Evidence from Romania // Outlook on Agriculture. 2020. Vol. 49 (1). Pp. 57-65. DOI:10.1177/0030727019861973. 67. Campbell O. A., Olurinola I. O., Oluwatobi S., Emiola T. O. Cooperative Society and Employees'Welfare // International Journal of Current Research. 2017. Vol. 9 (5). Pp. 50050-50055.

68. Янбых Р. Г., Сарайкин В. А. Оценка деятельности сектора сельскохозяйственных потребительских кооперативов на основе анализа показателей финансовой отчетности // Экономика сельскохозяйственных и перерабатывающих предприятий. 2017. № 12. С. 59-64. 
69. Головина С. Г., Смирнова Л. Н. Использование традиционной модели сельскохозяйственного кооператива в российской хозяйственной практике // Экономика сельскохозяйственных и перерабатывающих предприятий. 2020. № 6. С. 32-37. DOI: 10.31442/0235-2494-2020-0-6-32-37.

70. Cook M. L. A Life Cycle Explanation of Cooperative Longevity // Sustainability. 2018. Vol. 10 (5). P. 1586. DOI: 10.3390/su10051586.

71. Grashuis J. An Exploratory Study of Cooperative Survival: Strategic Adaptation to External Developments // Sustainability. 2018. Vol. 10 (3). P. 652. DOI: 10.3390/su10030652.

72. Головина С. Г., Смирнова Л. Н. Возможности использования новых моделей кооперативов в аграрной экономике России // Вестник Тюменского государственного университета. Социально-экономические и правовые исследования. 2020. Т. 6. № 1 (21). С. 322-344. DOI: 10.21684/2411-7897-2020-6-1-322-344.

\title{
Об авторах:
}

Светлана Георгиевна Головина ${ }^{1}$, доктор экономических наук, профессор, главный научный сотрудник института аграрно-экологических проблем и управления сельским хозяйством, ORCID 0000-0002-1157-8487, AuthorID 149863; +7909 146-40-64,kkrav84@mail.ru

Лидия Николаевна Смирнова ${ }^{2}$, ведущий научный сотрудник НИИ «Изучение проблем АПК», ORCID 0000-0002-7991-0802, AuthorID 904486; +7912 212-68-17, lidia-1311@mail.ru

${ }^{1}$ Уральский государственный аграрный университет, Екатеринбург, Россия

${ }^{2}$ Курганская государственная сельскохозяйственная академия имени Т. С. Мальцева, Лесниково, Россия

\section{Agricultural cooperation in the conditions of new challenges and threats: from theoretical discussion to economic practice}

\author{
S. G. Golovina ${ }^{1 凶}$, L. N. Smirnova ${ }^{2}$ \\ ${ }^{1}$ Ural State Agrarian University, Ekaterinburg, Russia \\ ${ }^{2}$ Kurgan State Agricultural Academy named after T. S. Maltsev, Lesnikovo, Russia \\ E-mail:kkrav84@mail.ru
}

\begin{abstract}
In the current socio-economic, political and institutional conditions, primarily in the context of new challenges and threats (such as sanctions restrictions, natural disasters, epidemics and pandemics), which determine high instability in the activities of agricultural producers, particular importance in the development of the agricultural economy, rural communities and rural areas moves to agricultural cooperation. As retrospective studies prove, agricultural cooperatives always become particularly popular in the most difficult periods for agriculture (and the economy as a whole), extremely actualizing at this time the corresponding theoretical and applied research. The study and analysis of scientific works concerning current state of agricultural cooperation, its problems and potential in improving of agricultural production and harmonious development of rural areas allows us to conclude that, Despite the presence (in the review materials presented to the scientific community) of the evolution of cooperative thought and generalizing discussions on the theory of cooperation descriptions, the achievements of recent years, nevertheless, did not find a detailed reflection in them. The purpose of this work is to summarize the most meaningful results of world-class research on the activities of agricultural cooperatives in a fluctuating (sometimes turbulent) environment, which are relevant (and acceptable) for the development of Russian cooperative practices in the face of existing challenges and threats. Results. A survey-analytical study, the results of which are presented in this article, made it possible (through a thorough analysis of the achievements of the cooperative theory over the past five years) to formulate and scientifically substantiate the main components of a new (integrated, interdisciplinary) approach to the development of Russian agricultural cooperation in the current institutional and market context, the basic elements of which are (1) taking into account the peculiarities of the socio-economic and institutional environment, (2) the multifunctionality of cooperative activities, (3) the specifics of ways to create cooperatives in different countries and spheres of activity, (4) the limitations of traditional and the prospects of new organizational models of agricultural cooperatives. Scientific novelty. The article offers a detailed review of foreign and Russian studies on various aspects of agricultural cooperation, notable by a rich history and comprehensive discussions, substantiated a new concept for the development of modern agricultural cooperatives, formulated conclusions that have theoretical novelty and applied value for use in domestic economic practice.
\end{abstract}

Keywords: theory of cooperation, agricultural cooperative, socio-economic environment, institutional and market conditions, challenges and threats, literature review. 
For citation: Golovina S. G., Smirnova L. N. Sel'skokhozyaystvennaya kooperatsiya v usloviyakh novykh vyzovov i ugroz: ot teoreticheskikh diskussiy k khozyaystvennoy praktike [Agricultural cooperation in the conditions of new challenges and threats: from theoretical discussion to economic practice] // Agrarian Bulletin of the Urals. 2021. No. 04 (207). Pp. 71-88. DOI: 10.32417/1997-4868-2021-208-05-71-88. (In Russian.)

Date of paper submission: 27.03.2021, date of review: 08.04.2021, date of acceptance: 26.04.2021.

\section{References}

1. Illiopoulos C., Cook M. L., Chadad F. Agricultural Cooperatives in Netchains // Journal of Chain and Network Science. 2016. Vol. 16 (1). Pp. 1-6. DOI: 10.3920/JCNS2016.x003.

2. Liang Q., Hendrikse G. Pooling and the Yardsticks Effect of Cooperatives // Agricultural Systems. 2016. Vol. 143. Pp. 97-105. DOI: 10.1016/j.agsy.2015.12.004.

3. Ménard C. Organization and Governance in the Agrifood Sector: How Can We Capture Their Variety? // Agribusiness. 2018. Vol. 34 (1). Pp. 142-160. DOI: 10.1002/agr.21539.

4. Grashuis J., Cook M. L. A Structural Equation Model of Cooperative Member Satisfaction and Long-term Commitment // International Food and Agribusiness Management Association. 2019. Vol. 22 (2). Pp. 247-263. DOI: 10.22434/IFAMR2018.0101.

5. Iliopoulos C., Valentinov V. Member Preference Heterogeneity and Systemlifeworld Dichotomy in Cooperatives: An Exploratory Case Study // Journal of Organizational Change. Management. 2017. Vol. 30 (7). Pp. $1063-1080$. DOI: 10.1108/JOCM-12-2016-0262.

6. Sobolev A. V., Brilon A. V., Ermilov M. M. Kooperatsiya v fokuse issledovateley: kooperativnaya model', povedenie i strategiya [Cooperation in the Focus of Researchers: Cooperative Model, Behavior and Strategy] // Fundamental and Applied Researches of the Cooperative Sector of the Economy. 2019. No. 3. Pp. 31-42. (In Russian.)

7. Puusa A., Hokkila K., Varis A. Individuality vs. Communality - A New Dual Role of Co-operatives? // Journal of Co-operative Organization and Management. 2016. Vol. 4 (1). Pp. 22-30. DOI: 10.1016/j.jcom.2016.02.002.

8. Briggeman B. C., Jacobs K. L., Kenkel P., Mckee G. J. Current Trends in Cooperative Finance // Agricultural Finance Review. 2016. Vol. 76 (3). Pp. 402-410. DOI: 10.1108/AFR-04-2016-0034.

9. Grashuis J. A Quantile Regression Analysis of Farmer Cooperative Performance // Agricultural Finance Review. 2018. Vol. 78 (1). Pp. 65-82. DOI: 10.1108/AFR-05-2017-0031.

10. Bijman J., Muradian R., Schuurman J. (eds.) Cooperatives, Economic Democratization and Rural Development. Edward Elgar Pub. Ltd., Cheltenham, UK, 2016. 310 p.

11. Kustepeli Y., Gulcan Y., Yercan M. et al. The Role of Agricultural Development Cooperatives in Establishing Social Capital // The Annals of Regional Science. Published online 20 January 2020. DOI: 10.1007/s00168-01900965-4.

12. Roth S., Valentinov V., Kaivo-oja J., Dana L.-A. Multifunctional Organisation Models: A Systems - Theoretical Framework for New Venture Discovery and Creation // Journal of Organizational Change Management. 2018. Vol. 31 (7). Pp. 1383-1400. DOI: 10.1108/JOCM-05-2018-0113.

13. Grashuis J. An Exploratory Study of Ownership and Governance Interrelationships in Traditional and Hybrid Farmer Cooperatives // Managerial and Decision Economics. 2018. Vol. 39 (6). Pp. 664-673. DOI: 10.1002/mde.2936.

14. Grashuis J., Cook M. L. An Examination of New Generation Cooperatives in the Upper Midwest: Successes, Failures, and Limitations // Annals of Public and Cooperative Economics. 2018. Vol. 89(4). Pp. 623-644. DOI: 10.1111/apce.12211.

15. Haddad N. O., Ton G., Sraïri M. T., Bijman J. Organisational Challenges of Moroccan Dairy Cooperatives and the Institutional Environment // International Journal on Food System Dynamics. 2017. Vol. 8 (3). Pp. 236-249. DOI: 10.18461/ijfsd.v8i3.835.

16. Hakelius K., Nilsson J. The Logic behind the Internal Governance of Sweden's Largest Agricultural Cooperatives // Sustainability. 2020. Vol. 12 (21). P. 9073. DOI: 10.3390/su12219073.

17. Royer A., Bijman J., Abebe G. K. Cooperatives, Partnerships and the Challenges of Quality Upgrading: A Case Study from Ethiopia // Journal of Co-operatives Organization and Management. 2017. Vol. 5 (1). Pp. 48-55. DOI: 10.1016/j.jcom.2017.04.001.

18. Cook M. L., Grashuis J. Theory of Cooperatives: Recent Developments. In: Routledge Handbook of Agricultural Economics. New York, NY: Routledge, 2018. Pp. 372-392.

19. Grashuis J., Su Y. A Review of the Empirical Literature on Farmer Cooperatives: Performance, Ownership and Governance, Finance, and Member Attitude // Annals of Public and Cooperative Economics. 2018. Vol. 90 (1). Pp. 77-102. DOI: 10.1111/apce.12205.

20. Snyder H. Literature Review as A Research Methodology: An Overview and Guidelines // Journal of Business Research. 2019. Vol. 104. Pp. 333-339. DOI: 10.1016/j.jbusres.2019.07.039.

21. Palmatier R. W., Houston M. B., Hulland J. Review Articles: Purpose, Process, and Structure // Journal of the Academy of Marketing Science. 2018. Vol. 46. Pp. 1-5. DOI: 10.1007/s11747-017-0563-4. 
22. Golovina S. G., Smirnova L. N. Nauchno-prakticheskie rekomendatsii po ispol'zovaniyu mezhdunarodnogo opyta razvitiya sel'skokhozyaystvennoy kooperatsii v otechestvennoy khozyaystvennoy praktike [Scientific and Practical Recommendations on the Use of International Experience in the Development of Agricultural Cooperation in Domestic Economic Practice]. Kurgan: Izd-vo KGSKhA, 2020. 273 p. (In Russian.)

23. Grashuis J., Cook M. L. Farmer Cooperatives as Systems of Attributes: An Analysis of Ownership and Investment Complementarities // Hendrikse G. W. J., Cliquet G., Ehrmann T., Windsperger J. (eds.) Management and Governance of Networks: Franchising, Cooperatives, and Strategic Alliances. Springer International Publishing: New York (NY, USA). 2017. Pp. 131-147. DOI: 10.1007/978-3-319-57276-5 8.

24. Antonova M. P., Potapova A. A. Sozdanie kooperativov po printsipu top-down: potentsial'nye oshibki [Development of Cooperative Farming: Pattern Leads to Haulers] // Russian Economic Developments. 2019. Vol. 26. (7). Pp. -56-64. (In Russian.)

25. Saraykin V. A., Yanbykh R. G. Analiz ustoychivosti kooperativnoy formy khozyaystvovaniya agrarnogo sektora Rossii v kontekste institutsional'noy teorii firmy [Sustainability Analysis of the Cooperative Form in Russian Agrarian Sector Under Institutional Theory of the Firm Context] // St Petersburg University Journal of Economic Studies. 2019. Vol. 35 (2). Pp. 251-268. DOI: 10.21638/spbu05.2019.204. (In Russian.)

26. Sobolev A. V., Pakhomov V. M., Rykalin A. S. Sel'skokhozyaystvennye kooperativy: institutsional'nyy i regional'nyy podtekst [Agricultural Cooperatives: Institutional and Regional Subtext] // Fundamental and Applied Researches of the Cooperative Sector of the Economy. 2020. No. 1. Pp. 90-100. (In Russian.)

27. Golovina S., Antonova M., Abilova E. Assessment of Agricultural Cooperatives' Performance in Russia: The Case of the Kurgan Region // Advances in Social Science, Education and Humanities Research. 2020. Vol. 392. Pp. 370-376. DOI: 10.2991/assehr.k.200113.077.

28. Mugwagwa I., Bijman J., Trienekens J. Typology of Contract Farming Arrangements: A Transaction Cost Perspective // Agricultural Economics Research, Policy and Practice in Southern Africa. 2020. Vol. 59 (2). Pp. 169187. DOI: $10.1080 / 03031853.2020 .1731561$.

29. Wolz A. Golovina S., Nilsson J., Hess S. Reviewing Changing Institutional Conditions for Private Farming in Russia // Outlook on Agriculture. 2016. Vol. 45 (2). Pp. 111-116. DOI: 10.1177/0030727016651214.

30. Hakelius K., Hansson H. Members' Attitudes towards Cooperatives and Their Perception of Agency Problems // International Food and Agribusiness Management Association. 2016. Vol. 19 (4). Pp. 1-14. DOI: 10.22434/ IFAMR2015.0219.

31. Sokoli O., Doluschitz R. Cooperative Evolvement through Political Era / Epoch: Albanian's Case and Comparisons // Economics of Agriculture. 2019. Vol. 66 (1). Pp. 189-204. DOI: 10.5937/ekoPolj1901189S.

32. Yu L., Nilsson J. Social Capital and Financial Capital in Chinese Cooperatives // Sustainability. 2019. No. 11 (8). P. 2415. DOI: 10.3390/su11082415.

33. Golovina S., Hess S., Nilsson J., Wolz A. Networking among Russian Farmers and their Prospects for Success // Post-Communist Economies. 2019. Vol. 31 (4). Pp. 48-499. DOI: 10.1080/14631377.2018.1537737.

34. Mwambi M., Bijman J., Mshenga P. Which Type of Producer Organization is (More) Inclusive? Dynamics of Farmers' Membership and Participation in the Decision-Making Process // Annals of Public and Cooperative Economics. 2020. Vol. 91 (2). Pp. 213-236. DOI: 10.1111/apce.12269.

35. Kontogeorgos A., Sergaki P., Chatzitheodoridis F. An Assessment of New Farmers' Perceptions about Agricultural Cooperatives // Journal of Developmental Entrepreneurship. 2017. Vol. 22 (1). Pp. 1750003(1)-1750003(13). DOI: 10.1142/S1084946717500030.

36. Saraykin V. A., Yanbykh R. G. Napravleniya sovershenstvovaniya organizatsii i effektivnogo razvitiya kooperatsii [Directions for improving the organization and effective development of cooperation] // APK: Ekonomika, Upravlenie. 2017. No. 6. Pp. 40-47. (In Russian.)

37. Medvedeva T. Assessment of Solvency and Financial Stability of Agricultural Consumer Cooperatives // Advances in Social Science, Education and Humanities Research. 2019. Vol. 392. Pp. 331-335. DOI: 10.2991/ assehr.k.200113.069.

38. Kurakin A., Visser O. Post-Socialist Agricultural Cooperatives in Russia: A Case Study of Top-Down Cooperatives in the Belgorod Region // Post-Communist Economies. 2017. Vol. 29 (2). Pp. 158-181. DOI: 10.1080/14631377.2016.1267974.

39. Bozhkov O. B., Nikulin A. M., Poleshchuk I. K. Sel'skaya kooperatsiya v Severnom Nechernozem'e: ofitsial'nye i neformal'nye praktiki [Agricultural cooperation in the Northern Non-Black-Earth Region: formal and informal practices] // RUDN Journal of Sociology. 2020. Vol. 20. No. 4. Pp. 889-904. DOI: 10.22363/2313-2272-2020-20-4889-904. (In Russian.)

40. Deng W., Hendrikse G., Liang Q. Internal Social Capital and the Life Cycle of Agricultural Cooperatives // Journal of Evolutionary Economics. 2021. Vol. 31 (1). Pp. 1-23. DOI: 10.1007/s00191-020-00690-8.

41. Feng L., Friis A., Nilsson J. Social Capital among Members in Grain Marketing Cooperatives of Different Sizes // Agribusiness. 2016. Vol. 32 (1). Pp. 113-126. DOI: 10.1002/agr.21427. 
42. Liang Q., Lu H., Deng W. Between Social Capital and Formal Governance in Farmer Cooperatives: Evidence from China // Outlook on Agriculture. 2018. Vol. 47 (1). Pp. 196-203. DOI: 10.1177/0030727018778603.

43. Buzdalov I. N. Vekovaya drama rossiyskoy kooperatsii (1917-2017) [The Age-Old Drama of Russian Cooperation (1917-2017)] // Agro-Food Policy in Russia. 2017. No. 5 (65). Pp. 2-10. (In Russian.)

44. Petrikov A. V. Adaptatsiya agroprodovol'stvennogo sektora k postpandemicheskoy real'nosti [Adaptation of the Agri-Foodsector to Post-Pandemic Reality] // Scientific Works of the Free Economic Society of Russia. 2020. Vol. 223. No. 3. Pp. 99-105. DOI: 10.38197/2072-2060-2020-223-3-99-105. (In Russian.)

45. Bijman J. Exploring the Sustainability of the Cooperative Model in Dairy: The Case of the Netherlands // Sustainability. 2018. Vol. 10 (7). P. 2498. DOI: 10.3390/su10072498.

46. Yanbykh R. G., Gataulina E. A. Otsenka izmeneniya potentsiala sel'skokhozyaystvennoy potrebitel'skoy kooperatsii v molochnoy otrasli za desyat' let (2006-2016 gody) [Assessment of Change a Potential of Agricultural Consumer Cooperation in the Dairy Industry in Ten Years (2006-2016)] // Fundamental and Applied Researches of the Cooperative Sector of the Economy. 2019. No 1. Pp. 19-25. (In Russian.)

47. Hooks T., McCarthy O., Power C. Macken-Walsh A. A Co-operative Business Approach in a Values-based Supply Chain: A Case Study of a Beef Co-operative // Journal of Co-operative Organization and Management. 2017. Vol. 5. Iss. 2. Pp. 65-72. DOI: 10.1016/j.jcom.2017.10.001.

48. Li L., Guo H., Bijman J., Heerink N. The Influence of Uncertainty on the Choice of Business Relationships: The Case of Vegetable Farmers in China // Agribusiness. 2018. Vol. 34. Pp. 597-615. DOI: 10.1002/agr.21540.

49. Skevas T., Grashuis J. Technical Efficiency and Spatial Spillovers: Evidence From Grain Marketing Cooperatives in the Us Midwest // Agribusiness. 2020. Vol. 36. Pp. 111-126. DOI: 10.1002/agr.21617.

50. Zhong Z., Zhang C., Jia F., Bijman J. Vertical Coordination and Cooperative Member Benefits: Case Studies of Four Dairy Farmers' Cooperatives in China // Journal of Cleaner Production 2018. Vol. 172. Pp. 2266-2277. DOI: 10.1016/j.jclepro.2017.11.184.

51. Loretts E., Golovina S., Smirnova L. Functioning Field of Farm Enterprises in Russia: Uncertainty and Risks. Proceedings of the International Scientific and Practical Conference «Digital Agriculture - Development Strategy» (ISPC 2019) // Advances in Intelligent Systems Research. 2019. Vol. 167. Pp. 470-475. DOI: 10.2991/ispc19.2019.106.

52. Uzun V. Ya., Shagayda N. I. Otsenka vliyaniya institutsional'nykh i strukturnykh izmeneniy na razvitie agrarnogo sektora Rossii [Evaluation of The Impact of Institutional and Structural Changes on the Development of the Russian Agricultural Sector] // Voprosy ekonomiki. 2019. No. 4. Pp. 39-58. DOI: 10.32609/0042-8736-2019-4-39-58. (In Russian.)

53. Yanbykh R., Saraikin V., Lerman Z. Changes in Russia’s Agrarian Structure: What Can We Learn from Agricultural Census? // Russian Journal of Economics. 2020. No. 6. Pp. 26-41. DOI: 10.32609/j.ruje.6.49746.

54. Golovina S. G., Loretts E. E., Smirnova L.N. Mnogofunktsional'nost' deyatel'nosti sel'skokhozyaystvennykh kooperativov [Multifunctionality of Agricultural Cooperatives Activities] // Agrarian Bulletin of the Urals. 2019. No. 3. Pp. 58-63. DOI: 10.32417/article_5ce405141f3952.34454910. (In Russian.)

55. Sobolev A., Kurakin A., Pakhomov V., Trotsuk I. Cooperation in Rural Russia: Past, Present and Future // Universe of Russia. 2018. Vol. 27 (1). Pp. 65-89. DOI: 10.17323/1811-038X-2018-27-1-65-89.

56. Šumylè D., Ribašauskienè E. Servitization of Lithuanian Agricultural Cooperatives // Management Theory and Studies for Rural Business and Infrastructure Development. 2017. Vol. 39 (4). Pp. 510-523. DOI: 10.15544/ mts.2017.35.

57. Yanbykh R., Saraikin V., Lerman Z. Cooperative Tradition in Russia: A Revival of Agricultural Service Cooperatives? // Post-Communist Economies. 2019. Vol. 31 (6). Pp. 751-771. DOI: 10.1080/14631377.2019.1607439.

58. Iliopoulos C., Valentinov V. Cooperative Longevity: Why Are So Many Cooperatives So Successful? // Sustainability. 2018. Vol. 10 (10). P. 3449. DOI: 10.3390/su10103449.

59. Nilsson J., Golovina S., Hess S., Wolz A. Governance of Production Cooperatives in Russian Agriculture // Annals of Public and Cooperative Economics. 2016. Vol. 87 (4). Pp. 541-562. DOI: 10.1111/apce.12123.

60. Cameron G., Rosado F. R. P., Mederos D. D. D. Agricultural Co-Operatives in Canada and Cuba: Trends, Prospects and Ways Forward // Environment, Development and Sustainability. 2020. No. 22. Pp. 643-660.

61. Morfi C., Nilsson J., Österberg H. Why Farmers Involve Themselves in Co-Operative District Councils // Annals of Public and Cooperative Economics. 2018. Vol. 89 (4). Pp. 581-598. DOI: 10.1111/apce.12206.

62. Nilsson J. Governance Costs and the Problems of Large Traditional Co-Operatives // Outlook on Agriculture. 2018. Vol. 47 (2). Pp. 87-92. DOI: 10.1177/0030727018761175.

63. Yu L., Huang W. Non-Economic Societal Impact or Economic Revenue? A Performance and Efficiency Analysis of Farmer Cooperatives in China // Journal of Rural Studies. 2020. Vol. 80. Pp. 123-134. DOI: 10.1016/j. jrurstud.2020.08.010.

64. Zhang S., Wolz A. Ding Y. Is There a Role for Agricultural Production Cooperatives in Agricultural Development? Evidence from China // Outlook on Agriculture. 2020. Vol. 49 (3). Pp. 256-263. DOI: 10.1177/0030727020913283. 65. Zaimova D., Doitchinova J., Zheliazkov G. Transition and Agricultural Cooperatives in Bulgaria // CBU International Conference Proceedings. 2017. Vol. 5. Pp. 499-507. DOI: 10.12955/cbup.v5.974. 
66. Wolz A., Mollers J., Micu M. M. Options for Agricultural Service Cooperatives in a Postsocialist Economy: Evidence from Romania // Outlook on Agriculture. 2020. Vol. 49 (1). Pp. 57-65. DOI:10.1177/0030727019861973. 67. Campbell O. A., Olurinola I. O., Oluwatobi S., Emiola T. O. Cooperative Society and Employees'Welfare // International Journal of Current Research. 2017. Vol. 9 (5). Pp. 50050-50055.

68. Yanbykh R. G., Saraykin V. A. Otsenka deyatel'nosti sektora sel'skokhozyaystvennykh potrebitel'skikh kooperativov na osnove analiza pokazateley finansovoy otchetnosti [The Evaluation of Agriculture Cooperative Sector Performance on the Base of the Analysis of their Financial Indicators] // Economy of agricultural and processing enterprises. 2017. No. 12. Pp. 59-64. (In Russian.)

69. Golovina S. G., Smirnova L. N. Ispol'zovanie traditsionnoy modeli sel'skokhozyaystvennogo kooperativa v rossiyskoy khozyaystvennoy praktike [Using the Traditional Model of an Agricultural Cooperative in Russian Economic Practice] // Economy of agricultural and processing enterprises. 2020. No. 6. Pp. 32-37. DOI: 10.31442/0235-2494-2020-0-6-32-37. (In Russian.)

70. Cook M. L. A Life Cycle Explanation of Cooperative Longevity // Sustainability. 2018. Vol. 10 (5). P. 1586. DOI: 10.3390/su10051586.

71. Grashuis J. An Exploratory Study of Cooperative Survival: Strategic Adaptation to External Developments // Sustainability. 2018. Vol. 10 (3). P. 652. DOI: 10.3390/su10030652.

72. Golovina S. G., Smirnova L. N. Vozmozhnosti ispol'zovaniya novykh modeley kooperativov v agrarnoy ekonomike Rossii [The Opportunities of New Cooperative Models Application in Russian Agricultural Economy] // Tyumen State University Herald. Social, Economic, and Law Research. 2020. Vol. 6. No. 1 (21). Pp. 322-344. DOI: 10.21684/2411-7897-2020-6-1-322-344. (In Russian.)

\section{Authors'information:}

Svetlana G. Golovina ${ }^{1}$ doctor of economics, professor, chief researcher of the research institutes of agricultural and environmental problems and agricultural management, ORCID 0000-0002-1157-8487, AuthorID 149863; +7909146-40-64, kkrav84@mail.ru

Lidiya N. Smirnova ${ }^{2}$, candidate of pedagogical sciences, leading researcher of the research institute "Study of AgroIndustrial Complex Problems", ORCID 0000-0002-7991-0802, AuthorID 904486; + 7912 212-68-17,

lidia-1311@mail.ru

${ }^{1}$ Ural State Agrarian University, Ekaterinburg, Russia

${ }^{2}$ Kurgan State Agricultural Academy named after T. S. Maltsev, Lesnikovo, Russia 